\title{
Breakthrough Curves and Miscible Displacement of Cadmium Through Double-Layered Reclaimed Soils Amended with Macroporous Granule
}

\author{
Hye Jin Kim, Jin-Hee Ryu ${ }^{1}$, Si-Ju Kim ${ }^{1}$, Misuk Park, and Doug Young Chung* \\ Department of Bioenvironmental Chemistry College of Agriculture and Life Science Chungnam \\ National University Daejeon Korea 305-764 \\ ${ }^{I}$ Department of Rice and Winter Cereal Crop, NICS, RDA, Iksan 570-080, Korea
}

\begin{abstract}
Transport of heavy metals such as $\mathrm{Cd}$ is affected by several rate-limiting processes including adsorption and desorption by exchange reactions in soils. In this study, column transport and batch kinetic experiments were performed to assess Cd mobility in a double-layered soil with a reclaimed saline and sodic soil (SSS) as top soil and macroporous granule (MPG) as a bottom layer. For individual soil layer having different physical and chemical properties, $\mathrm{Cd}$ was considered to be nonlinear reactivity with the soil matrix in layered soils. The dispersive equation for reactive solutes was solved with three types of boundary conditions for the interface between soil layers. The adsorption of $\mathrm{Cd}$ with respect to the saline-sodic sandy loam and the MPG indicated that the nature of the sites or the mechanisms involved in the sorption process of $\mathrm{Cd}$ was different and the amounts of $\mathrm{Cd}$ for both of samples increases with increasing amounts of equilibrium concentration whereas the amount of Cd adsorbed in saline-sodic sandy loam soil was higher than that in MPG. The results of breakthrough curve indicating relative $\mathrm{Cd}$ retardation accompanied by layer material and sequence during leaching showed that the number of pore volumes to reach the maximum relative concentration of 1 increased in the order of MPG, SSS, and double layer of SSS-MPG. Breakthrough curves (BTCs) from column experiments were well predicted with our double-layered model where independently derived solute physical and retention parameters were implemented.
\end{abstract}

Key words: Transport, Cd, Double-layered Soil, Macroporous Granule

\section{Introduction}

Environmental issues associated with heavy metals that would mainly include the transition metals, some metalloids, lanthanoids, and actinides over more than the past two decade, because the soil is a key element in controlling the fate of heavy metals in the environment due to bioaccumulation which means an increase in the concentration of a chemical in a biological organism over time (Duffus, 2002).

Heavy metals which naturally occur in the ecosystem with large variations in concentration cannot be degraded or destroyed, and are particularly severe in their action such as contaminating plants and entering the food chain from the soils, the presence of cadmium identified as the most critical metal due to its human toxicity can be

\footnotetext{
Received : January 13. 2011 Accepted : January 27. 2011

*Corresponding author : Phone: +82428216739

E-mail: dychung@cnu.ac.kr
}

accumulated in the plant root zone and also results in decreased crop yield (Rao and Mathur, 1994). Chlopecka and Adriano (1996) also reported that the availability of the heavy metal for transport and biological uptake may be inferred through the determination of the element distribution in the soil solid fractions as a function of its chemical reactions. Therefore, it is important to understand the transport behavior of heavy metals in soils (Hinz and Selim, 1994).

A number of scientists studied soil properties that significantly affect the behavior of heavy metals such as $\mathrm{Cd}$ which is of potential concern as an environmental contaminant. It exhibits adverse effects on biological processes in humans, animals, and plants (Buchter et al. 1989; Kabata-Pendias and Mukherjee, 2007). Selim et al., (1992) reported that heavy metals in the soil environment involved a series of complex chemical and biological interactions. Several of the reactions include oxidationreduction, precipitation and dissolution, volatilization, and 
surface and solution phase complexation.

For several decades the transport of dissolved chemicals in layered soils have been studied (Selim et al., 1977; Bosma and van der Zee, 1992). Because of kinetic sorption or ion exchange and hysteretic sorption physical nonequilibrium processes such as soil heterogeneity, preferential flow, and kinetic diffusion or chemical nonequilibrium processes may influence mobility of heavy metals in soil systems (Garrido et al., 2008).

Movement of reactive solute with sorption processes through double-layer system can be investigated through numerical methods using either an equilibrium or kinetic approach. Because of the resulting conceptual and mathematical simplification, many transport models assume local chemical equilibrium is valid for describing sorption reactions (Valocchi, 1985). However, local equilibrium conditions are only valid when sorption is linear, reversible, and not kinetically limited where solute transport occurs only in a homogeneous porous medium.

The objectives of this investigation were to theoretically examine the effects of stratification sequence on the mobility and fate of the heavy metals through water-saturated double-layered soil system under steady state flow. The two-layered soils consisted of saline-sodic sandy loam soil as surface layer representing a reclaimed land and macroporous granule layer generated from a coal power plant as bottom layer enhancing the mobility of solute transported from the upper layer. We assumed that each soil layer was homogeneous and isotropic with soil water and solutesorption properties known.

\section{Theory}

As shown in Fig. 1, two layers in a soil column denoted by $L_{1}$ and $L_{2}$ have specific, but not necessarily the same, water content, bulk density, and reactive properties under steady-state water flow perpendicular to the soil layers. The convective and dispersive equation (CDE) suggested by Selim et al., (1977) was adopted with the initial conditions governing reactive solute transport in the ith layer as shown in Eq. (1) and (2), respectively.

The reversible solute retention from the soil solution is represented by the term $\partial \mathrm{S} / \partial \mathrm{t}$ on the left side of Eq. (1) while the irreversible solute removed from soil solution is expressed by the term $\mathrm{Q}$ on the right side of Eq. (1).

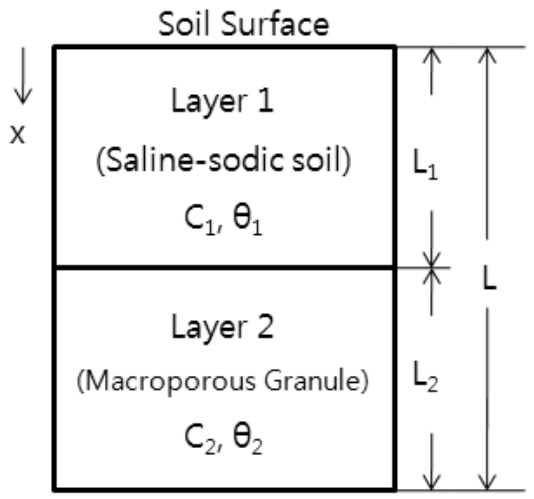

Fig. 1. Schematic diagram of a two-layered soil.

$$
\rho \frac{\partial S_{i}}{\partial t}+\theta_{i} \frac{\partial C_{i}}{\partial t}=\frac{\partial}{\partial x} \theta_{i} D_{i} \frac{\partial C_{i}}{\partial x}-q \frac{\partial C_{i}}{\partial x}(\leq \mathrm{x} \leq \mathrm{Li}, \mathrm{I}=1,2)
$$

where $\mathrm{C}$ is resident concentration of solute in soil solution $\left(\mu \mathrm{g} \mathrm{cm}^{-3}\right), \mathrm{S}$ is amount of solute adsorbed by the soil matrix $\left(\mu \mathrm{g} \mathrm{g}^{-1}\right), \rho$ is soil bulk density $\left(\mathrm{g} \mathrm{cm}^{-3}\right)$, $\theta$ is volumetric soil water content $\left(\mathrm{cm}^{3} \mathrm{~cm}^{-3}\right), \mathrm{D}$ is solute dispersion coefficient $\left(\mathrm{cm}^{2} \mathrm{~d}^{-1}\right), \mathrm{q}$ is Darcy soil-water flow velocity $\left(\mathrm{cm} \mathrm{d}^{-1}\right), Q$ is a sink or source for irreversible solute interaction $\left(\mu \mathrm{g} \mathrm{cm}^{-3} \mathrm{~d}^{-1}\right), \mathrm{x}$ is distance from the soil surface $(\mathrm{cm})$, and $\mathrm{t}$ is time $(\mathrm{d})$.

Each soil layer is initially solute free as shown in Eq. (2).

$$
\begin{aligned}
& \mathrm{S}_{\mathrm{I}}=\mathrm{S}_{\mathrm{II}}=0(\mathrm{t}=0) \\
& \mathrm{C}_{\mathrm{I}}=\mathrm{C}_{\mathrm{II}}=0(\mathrm{t}=0)
\end{aligned}
$$

Eq. (3) and (4) can be used as the boundary conditions for Layer I at the surface of soil column when flux is known. Under these conditions, the solute will break through the layered soils when an input pulse of solute solution having a concentration $\mathrm{Co}$ and for a time duration $\operatorname{To}(d)$ is applied at the inlet.

$$
\begin{array}{lll}
q C_{o}=q C_{I}-\theta_{I} D_{I} \frac{\partial C_{I}}{\partial x} \quad(\mathrm{x}=0, \mathrm{t} \leq \mathrm{To}) & \text { Eq. (3) } \\
0=q C_{I}-\theta_{I} D_{I} \frac{\partial C_{I}}{\partial x} \quad(\mathrm{x}=0, \mathrm{t}>\mathrm{To}) & \text { Eq. (4) }
\end{array}
$$

The boundary condition for Layer II at the bottom of the soil column $(\mathrm{x}=\mathrm{L})$ is

$$
\frac{\partial C_{I I}}{\partial x}=0 \quad(\mathrm{x}=0, \mathrm{t} \geq \mathrm{To})
$$


Another $\mathrm{BC}$ needed in this investigation is the $\mathrm{BC}$ at the interface between $L_{1}$ and $L_{2}$ because a discontinuity in concentration develops when BCs applied at the soil surface is used. The interface condition will result in a continuous concentration profile across the boundary interface at the expense of solute mass balance. Due to the limitations of two different conditions, the condition below is used in this experiment as used in Zhou and Selim (2001).

$$
\left.\theta_{I} D_{I} \frac{\partial C_{I}}{\partial x}\right|_{x \rightarrow L_{I}^{-}}=\left.\theta_{I I} D_{I I} \frac{\partial C_{I I}}{\partial x}\right|_{x \rightarrow L_{I}^{+}}(\mathrm{t}>0) \quad \text { Eq. (6) }
$$

\section{Solute-Retention Mechanisms}

To describe the reversible retention term, $\partial \mathrm{S} / \partial \mathrm{t}$, in Eq. (1), Langmuir-type retention along with retardation factor (Eq. 8) as used Zhou and Selim (2001) was considered as follows:

$$
\frac{S}{S_{\max }}=\frac{k C}{1+k C}
$$

where $\mathrm{S}_{\max }$ is the total adsorption capacity ( $\mu \mathrm{g} \mathrm{g}^{-1}$ soil) and $k$ is a Langmuir affinity coefficient $\left(\mathrm{cm}^{3} \mathrm{~g}^{-1}\right)$. The retardation factor is concentration-dependent and given by

$$
R=R(C)=1+\frac{\rho}{\theta}\left[\frac{k S_{\max }}{(1+k C)^{2}}\right]
$$

The governing Eq. (1) subject to conditions (2) through
(5), and the BCs at the interface between two definitely distinct layers were implemented in a way similar to that of Zhou and Selim (2001).

\section{Materials and Methods}

Saline-sodic sandy loam soil (SSS) obtained from the surface of the Saemangum reclaimed area was air dried, mixed, and passed through a 2-mm screen. This was analyzed for $\mathrm{pH}$ using 1:5 soil to water ratio, for organic matter using the acid dichromate method, and for CEC of the soils by ammonium acetate method. An acidwashed MPG as packing material for bottom layer was chosen as a nonreactive matrix because of the absence of clay. The particle size of MPG was less than $2 \mathrm{~mm}$ in diameter. The soil particle distribution and chemical properties of the soil sample were shown in Table 1 . The concentrations of heavy metals in MPG previously washed at the production site located in Seochun, Chungnam were in Table 2.

Adsorption Isothems of Cd Batch adsorption isotherms for $\mathrm{Cd}$ were determined with triplicated 10-g quantities of saline-sodic soil and MPG, equilibrated for $24 \mathrm{~h}$ with $50 \mathrm{~mL}$ of $\mathrm{Cd}$ solutions ranging from 0 to $5.0 \mathrm{cmol}_{\mathrm{c}} \mathrm{L}^{-1}$. Following equilibration, the solid and liquid phases were separated by centrifugation at $3750 \mathrm{rpm}$ for 15 minutes. The total soluble metal concentrations in the clear supernatants were determined by ICP. The amount of metal adsorbed was determined as the difference between

\begin{tabular}{|c|c|c|c|c|c|c|c|c|c|c|c|c|c|}
\hline \multirow{2}{*}{ Sample } & \multirow{2}{*}{$\begin{array}{c}\mathrm{pH} \\
(1: 5)\end{array}$} & \multirow{2}{*}{ 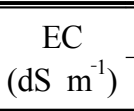 } & \multirow{2}{*}{$\frac{\text { Avg. } \mathrm{P}_{2} \mathrm{O}_{5}}{7.4}$} & \multirow{2}{*}{$\frac{\mathrm{OM}}{\left(\mathrm{g} \mathrm{kg}^{-1}\right)}$} & \multirow{2}{*}{$\frac{\mathrm{CEC}}{\left(\mathrm{cmol}_{\mathrm{c}} \mathrm{kg}^{-1}\right)}$} & \multicolumn{4}{|c|}{ Ex.-Cations $\left(\mathrm{cmol}_{\mathrm{c}} \mathrm{kg}^{-1}\right)$} & \multicolumn{3}{|c|}{ Soil particle distribution (\%) } & \multirow{2}{*}{$\begin{array}{c}\text { Soil } \\
\text { Texture }\end{array}$} \\
\hline & & & & & & 9.1 & $\mathrm{Ca}$ & $\mathrm{Mg}$ & $\mathrm{Na}$ & Sand & Silt & Clay & \\
\hline SSS & 7.4 & 22.5 & 8.4 & 7.5 & 3.95 & 2.25 & 3.9 & 7.2 & 23.8 & 49.3 & 43.8 & 6.9 & $\begin{array}{l}\text { Sandy } \\
\text { Loam }\end{array}$ \\
\hline MPG & 9.1 & 2.83 & - & - & 0.64 & 0.09 & 0.42 & 0.51 & 1.27 & 100 & - & - & - \\
\hline
\end{tabular}
initial concentration and final equilibration of $\mathrm{Cd}$ in

Table 1. Physical and chemical properties of a reclaimed soil samples used in this experiment.

Table 2. Concentrations of heavy metals in an coal bottom washed at production site.

\begin{tabular}{clcccccccc}
\hline \hline \multirow{2}{*}{ MPG } & & $\mathrm{Cd}$ & $\mathrm{Cr}$ & $\mathrm{Cu}$ & $\mathrm{Mn}$ & $\mathrm{Ni}$ & $\mathrm{Pb}$ & $\mathrm{Zn}$ \\
\cline { 3 - 10 } & & & & & & $(\mathrm{ppm})$ & & & \\
\hline \multirow{2}{*}{ w/o Organic-C } & Exchangeable & 0.1 & 0.4 & 2.9 & 27 & 0.8 & $\mathrm{ND}$ & $\mathrm{ND}$ \\
& Water-soluble & $\mathrm{ND}$ & 0.1 & $\mathrm{ND}$ & $\mathrm{ND}$ & $\mathrm{ND}$ & $\mathrm{ND}$ & 0.7 \\
\hline \multirow{2}{*}{ w/ Organic-C } & Exchangeable & 0.1 & 0.85 & 6.55 & 39 & 1.95 & $\mathrm{ND}$ & 4.25 \\
& Water-soluble & $\mathrm{ND}$ & 0.05 & 0.05 & 0.05 & $\mathrm{ND}$ & $\mathrm{ND}$ & $\mathrm{ND}$ \\
\hline
\end{tabular}


Table 3. Experimental conditions for the double-layered soil column.

\begin{tabular}{|c|c|c|c|c|c|c|c|c|}
\hline \multicolumn{8}{|c|}{ Specification of layer } & \multirow{3}{*}{ Influent } \\
\hline \multicolumn{4}{|c|}{ Upper } & \multicolumn{4}{|c|}{ Bottom } & \\
\hline $\begin{array}{l}\text { Packing } \\
\text { Material }\end{array}$ & $\begin{array}{l}\text { Length } \\
\text { (cm) }\end{array}$ & $\begin{array}{c}\mathrm{BD} \\
\left(\mathrm{g} \mathrm{cm}^{-1}\right)\end{array}$ & $\begin{array}{l}\text { Water flux } \\
\left.(\mathrm{cm} \mathrm{hr})^{-1}\right)\end{array}$ & $\begin{array}{l}\text { Packing } \\
\text { Material }\end{array}$ & $\begin{array}{l}\text { Length } \\
(\mathrm{cm})\end{array}$ & $\begin{array}{c}\mathrm{BD} \\
\left(\mathrm{g} \mathrm{cm}^{-1}\right)\end{array}$ & 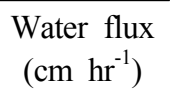 & \\
\hline $\begin{array}{l}\text { Saline-sodic } \\
\text { sandy loam }\end{array}$ & 20 & 1.28 & 0.79 & MPG & 20 & 1.08 & 1150 & $\begin{array}{l}\mathrm{Cd}\left(\mathrm{NO}_{3}\right)_{2} \rightarrow \text { Deionzed } \mathrm{H}_{2} \mathrm{O} \\
\quad \text { or } 1 \mathrm{cmol}_{\mathrm{c}} \mathrm{L}^{-1} \mathrm{Cd}\left(\mathrm{NO}_{3}\right)_{2}\end{array}$ \\
\hline
\end{tabular}

solution. Adsorption isotherms of Cd ware obtained by the same procedures as of reclaimed soil.

Breakthrough Curves of Cd The breakthrough curves of Cd was investigated through a single layer of MPG and SSS and a double layer of MPG and SSS soil column (DSM). A saline-sodic sandy loam soil and acid-washed MPG were packed for upper and bottom layers in small increments into acryl columns $(60 \mathrm{~cm}$ long and $6.4 \mathrm{~cm}$ in diameter). Each soil column consisted of two distinct layers: a Moonpo saline-sodic sandy loam layer and acid-washed MPG layer. The specification of each layer was listed in Table. 3. Then the layered soil column was slowly saturated from the bottom with deionized water until water was appeared on the surface of the column. Upon saturation, input solutions of 1.0 $\mathrm{cmol}_{\mathrm{c}} \mathrm{L}^{-1}$ of $\mathrm{Cd}$ as $\mathrm{Cd}\left(\mathrm{NO}_{3}\right)_{2}$ were introduced to each soil column by maintaining the water level $10 \mathrm{~cm}$ above the soil surface of the column until the concentration of $\mathrm{Cd}$ in effluent was similar to that of the input solution. The effluent was collected in approximately $2 \mathrm{hr}$ interval and analyzed for $\mathrm{Cd}$ concentrations in the effluent using inductively coupled plasma. After obtaining BTC for each treatment, $\mathrm{Ca}\left(\mathrm{NO}_{3}\right)_{2}$ or deionized water was introduced to observe miscible displacement pattern of $\mathrm{Cd}$ from a soil column. The procedures for collection and analysis of $\mathrm{Cd}$ in effluent were same as the procedure of BTC above.

\section{Results and Discussion}

Adsorption Adsorption isotherms of cadmium were determined in the saline-sodic sandy loam and in the MPG, respectively. The adsorption of Cd with respect to the saline-sodic sandy loam (SSS) and the MPG could indicate that the nature of the sites or the mechanisms involved in the sorption process of $\mathrm{Cd}$ was different in Fig. 2. The amounts of $\mathrm{Cd}$ for both of samples increased

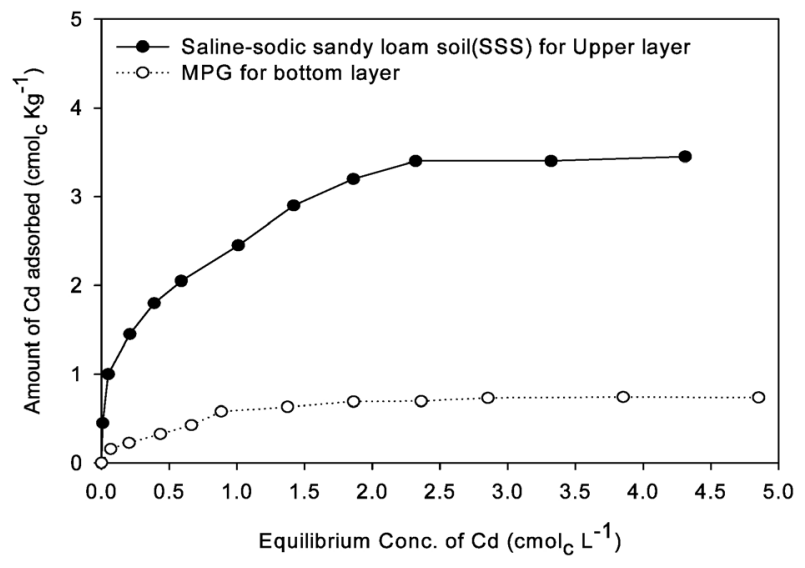

Fig. 2. Adsorption isotherms of $\mathrm{Cd}$ in a SSS and a MPG.

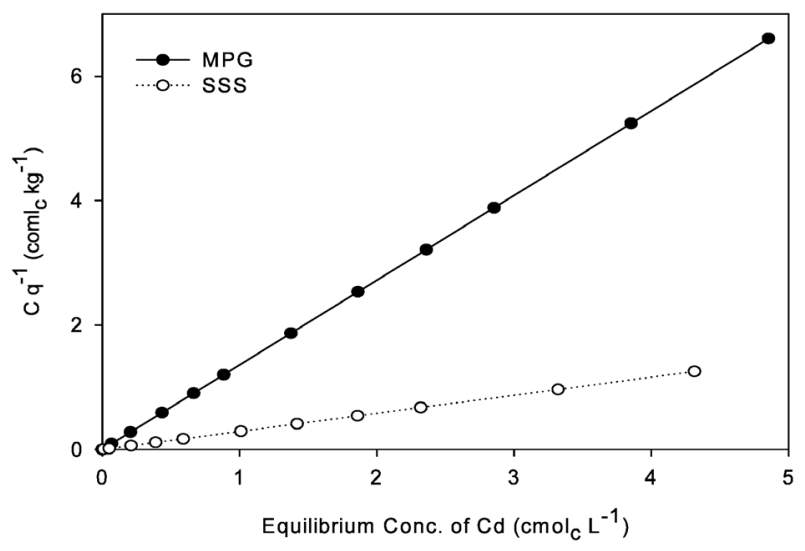

Fig. 3. Langmuir isotherm plots for Cd on SSS and on the MPG.

with increasing amounts of equilibrium concentration. The maximum amounts of $\mathrm{Cd}$ in this given condition were $3.45 \mathrm{cmol}_{\mathrm{c}} \mathrm{kg}^{-1}$ and $0.74 \mathrm{cmol}_{\mathrm{c}} \mathrm{kg}^{-1}$ for SSS and MPG, respectively, indicating that the amount of $\mathrm{Cd}$ adsorbed in SSS was much higher than that in MPG. Also, the results showed that the maximum adsorption of Cd for SSS and MPG were slightly lower than CECs of SSS and MPG.

Generally $\mathrm{Cd}$ adsorption isotherms are still described by the Langmuir equation. The results showed that $\mathrm{Cd}$ adsorptions on SSS and on the MPG were better fitted 
by the Langmuir equation in Fig. 3, indicating that adsorption sites are homogeneously distributed on the surface of the solid phase as observed by Altin et al. (1998).

Breakthrough Curves Breakthrough curves of $\mathrm{Cd}$ for the SSS and the MPG as a single layered soil and the SSS (top)-the MPG (bottom) as a double-layered soil where layers were reactive and nonlinearly adsorptive were reported in Fig. 4.

The breakthrough curves of all three soil columns in Fig. 4 confirmed that the sorption processes of $\mathrm{Cd}$ through SSS and MPG were different. Generally, Cd concentrations in the eluate increased with increasing pore volume of solution passing through the soil column until its value was the same as the influent solution while the pore volumes to reach the maximum relative concentration of 1 tended to lag by 1.42, 3.73, and 4.27 for MPG, SSS, and DSM, respectively. The results showed that $\mathrm{Cd}$ retention for the properties of material and layer was significantly correlated with adsorption capacity of the respective material in each layer. Especially the pore volumes of BTC for DSM to reach the maximum relative concentration of 1 were approximately 4.24, indicating that approximately 0.54 greater than that for the single layer of SSS. From these results we could concluded that different breakthrough curves of $\mathrm{Cd}$ were influenced by sorption process through the soil layers which contained specific layer materials.

The cumulative amount of $\mathrm{Cd}$ calculated by multiplying volume of effluent collected at the bottom of the soil column by difference between the concentrations of influent initially added at the top of the soil column and equilibrium concentrations of effluent collected at the bottom of the soil column was obtained from the relative concentration of $\mathrm{Cd}$ in the effluent. The results showed that the maximum amount of $\mathrm{Cd}$ were approximately $0.81,2.64$, and $2.98 \mathrm{cmol}_{\mathrm{c}} \mathrm{kg}^{-1}$ for MPG, SSS, and DSM, indicating that the calculated maximum amount of $\mathrm{Cd}$ by soils in columns were slightly less than those observed from adsorption isotherms as shown in Fig. 2.

On the other hand, $\mathrm{Cd}$ in a soil column was distributed between strongly retained forms on the sorption site of surface of soil particles and weakly retained forms as solution phase in soil pores. Types of Cd-adsorption whether strongly or weakly retained in a soil column could be identified by displacing $\mathrm{Cd}$ in soils with solution

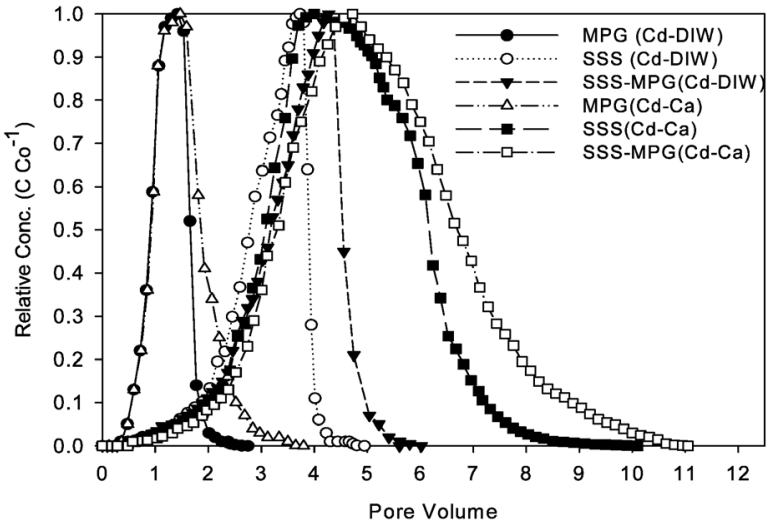

Fig. 4. Breakthrough curves of Cd for MPG, SSS, and double-layered SSS-MPG. $\mathrm{Cd}\left(\mathrm{NO}_{3}\right)_{2}$ as $\mathrm{Cd}$ was preceded and followed by $\mathrm{Cd}$-free deionized water or $0.1 \mathrm{~N} \mathrm{Ca}\left(\mathrm{NO}_{3}\right)_{2}$ to leach $\mathrm{Cd}$ retained in soils out from a soil column.

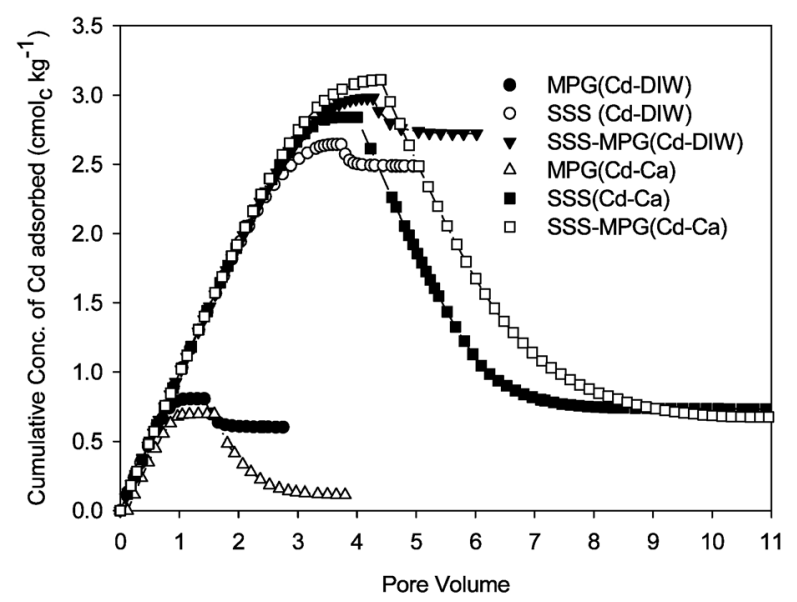

Fig. 5. Cumulative amount of $\mathrm{Cd}$ adsorbed for MPG, SSS, and SSS-MPG. $\mathrm{Cd}\left(\mathrm{NO}_{3}\right)_{2}$ was preceded and followed by deionized water or $1 \mathrm{cmol}_{\mathrm{c}} \mathrm{L}^{-1} \mathrm{Ca}\left(\mathrm{NO}_{3}\right)_{2}$ to leach $\mathrm{Cd}$ retained in soils out from a soil column.

such as soluble phase by deionized water or exchangeable by exchanging solution.

As shown in Fig. 4, the pore volumes of deionized water to remove $\mathrm{Cd}$ in soil column were smaller than those of $1 \mathrm{cmol}_{\mathrm{c}} \mathrm{L}^{-1} \mathrm{Ca}\left(\mathrm{NO}_{3}\right)_{2}$ to remove $\mathrm{Cd}$ in exchangeable site for all MPG, SSS, and DSM, respectively. The cumulative amount of $\mathrm{Cd}$ displaced by deionized water were approximately $0.206,0.156$. and $0.259 \mathrm{cmol}_{\mathrm{c}} \mathrm{kg}^{-1}$ soil while those of $\mathrm{Cd}$ by $1 \mathrm{cmol}_{\mathrm{c}} \mathrm{L}^{-1} \mathrm{Ca}\left(\mathrm{NO}_{3}\right)_{2}$ were $0.584,2.11,2.43 \mathrm{cmol}_{\mathrm{c}} \mathrm{kg}^{-1}$ for all MPG, SSS, and DSM, respectively. The differences between water soluble and exchangeable, that is, adsorbed phase in soil column, were $0.378,1.95,2.18 \mathrm{cmol}_{\mathrm{c}} \mathrm{kg}^{-1}$ for all MPG, SSS, and DSM. Therefore we concluded that more than $90 \%$ of $\mathrm{Cd}$ in soil column was exchangeable site that was 
relatively strongly adsorbed on the surface of soil particles.

To verify our results on the basis of numerical simulations, we conducted transport experiments for reactive Cd. Efforts were made to maintain an experimental transport condition consistent under the different layer material or layer characteristics. The difficulties encountered in maintaining a constant pore volume because of difference in porosity between the SSS and MPG due to internal pore in PMG. The water content was changed from saturated to unsaturated due to significant decrease in flux as water moved from layer of SSS to layer MPG which hold more pore volume than that of SSS. These results showed that, for all unsaturated profiles considered, the use of average water contents provided identical concentration distributions to those obtained where the actual water content distributions were used. Thus, when a steady water flux $\mathrm{q}$ is maintained through the profile, concentration distributions of reactive solutes at a given location in the soil profile can be predicted with average water contents within unsaturated soil layers. However the BTCs of effluent were not significantly affected by the characteristics of layer regardless of whether a single or double layer was encountered. The BTCs for Cd transport showed a relatively sharp front (adsortion) and tailing (desorption) for low cation exchange capacity. Predicted results show a shift to the left of measured BTC, indicating little retardation with a peak concentration close to unity.

\section{Summary and Conclusion}

From this investigation, we presented breakthrough results of reactive solutes in layered soil with emphasis on onnlinear reactivity with the soil matrix. Physical and chemical properties of each soil layer were assumed to differ significantly from one another. For all parameter values used in this study, the results indicated that the BTCs are similar regardless of the layering materials or characteristics whereas breakthrough curves show

that in the sorption process two different site types or two different mechanisms are involved. In the case investigated both methods show that cadmium is sorbed from the soil solution in larger amounts that sorption mechanisms are different for the two layer materials while MPG as bottom layer slightly enhances Cd desorption from the soil column.

\section{Acknowledgement}

The financial support from ITEP of Korea under grant (109185-03-2-CG000) is highly appreciated.

\section{References}

Altin, O., H.O. Ötzbelge, and T. Dogut. 1998. Use of general adsorption isotherms for heavy metal-clay mineral interactions. Journal of Colloid \& Interface Science, 198:130-140. doi: 10.1006/jcis.1997.5246.

Bosma, W.J.P., E.A.T.M. Sjoerd, and van der Zee. 1992. Analytical approximations for nonlinear adsorbing solute transport in layered soils. J.1 of Contam.t Hydrology. 10(2): 99-118.

Buchter, B., C. Hinz, M. Gfeller, and H. Flühler. 1996. Cadmium Transport in an Unsaturated Stony Subsoil Monolith. Soil Sci. Soc. of Am. J. 60:716-721.

Chlopecka, A. and D.C. Adriano. 1997. Influence of zeolite, apatite and $\mathrm{Fe}$-oxide on $\mathrm{Cd}$ and $\mathrm{Pb}$ uptake by crops. Sci Total Environ. 207(3):195-206.

Duffus, J.H. 2002 "HEAVY METALS"- MEANINGLESS TERM? Pure Appl. Chem. 74(5):793-807.

Garrido, F., S. Serrano, C.G. Campbell, L. Barrios, and M.T. García-González. 2008. Evidence of Physical and Chemical Nonequilibrium in Lead and Cadmium Transport and Sorption in Acid Soil Soil. Sci. Soc. of Am. J. 72:1434-1444.

Hinz, C. and Selim, H.M. 1994. Transport of $\mathrm{Zn}$ and $\mathrm{Cd}$ in soils:experimental evidence and modeling approaches. Soil Sci. Soc. of Am. J. 58:1316-1327.

Kabata-Pendias, A. and A.B. Mukherjee. 2007. Trace Elements from Soil to Human. Berlin: Springer-Verlag.

Leij, F.J., J.H. Dane, and M.Th. van Genuchten. 1991. Mathematical analysis of one-dimensional solute transport in a layered soil profile. Soil Sci. Soc. of Am. J. 55: 944-953.

Mehra, O.P. and M.L. Jackson. 1960. Iron oxide removal from soils and clays by a dithionite citrate system buffered with sodium bicarbonate. Clays Clay Miner. 7:313-317.

Rao Sandhya and Shashi Mathur. 1994. Modeling Heavy Metal (Cadmium) Uptake by Soil-Plant Root System. J. Irrig. and Drain. Engrg. 120(1):89-96.

Selim, H.M. and R.S. Mansell. 1976. Analytical solution of the equation of reactive solutes through soils, Reply. Water Resourc. Res. 13:703-704.

Selim, H.M., M.C. Amacher, and I.K. Iskandar. 1989. Modeling the Transport of Chromium (VI) in Soil Columns Soil. Sci. Soc. Am. J. 53:996-1004.

Selim, H.M., J.M. Davidson, and P.S.C. Rao. 1977. Transport of reactive solutes through doublelayered soils. Soil. Sci. Soc. Am. J. 41:3-10.

Selim, H.M., B. Buchter, C. Hinz, and L. Ma. 1992 Modeling the Transport and Retention of Cadmium in Soils: Multireaction and Multicomponent Approaches. Soil Sci. Soc. of Am. 
J. 56:1004-1015.

Valocchi, A.J. 1985. Validity of the local equilibrium assumption for modeling sorbing solute transport through homogeneous soils. Wat. Resour. Res. 21:808-820.
Zhou, L. and H.M. Selim. 2001. Solute Transport in Layered Soils: Nonlinear and Kinetic Reactivity. Soil Sci. Soc. of Am. J. 65:1056-1064. 